\title{
NEWS
}

\section{Vaccine venture boosts health hopes}

\author{
Industry and academia join forces to develop cheap jabs against diseases that afflict the poorest.
}

US pharmaceutical giant Merck and Company and the UK Wellcome Trust will create a joint, not-for-profit $£ 90$-million (US\$150-million) research centre in India to develop affordable vaccines against diseases that afflict the poor - including neglected diseases for which inadequate or no vaccines exist. The move marks the first time that a major medical-research charity and a pharmaceutical company have directly partnered to create vaccines aimed at low-income countries.

"It's a tremendous development," says Adel Mahmoud, a former president of Merck Vaccines and now a professor at Princeton University in New Jersey. Unlike drugs for neglected diseases, he says, "vaccines for neglected diseases have not been given any significant attention over the years."

The new research centre will be named after the late Maurice Hilleman, a Merck scientist who developed more than 40 vaccines, including against measles and hepatitis B. Its location in India has yet to be selected, but it is expected to open by the end of next year.

The centre will be headed by Altaf Lal, currently health attaché at the US embassy in New Delhi and the South Asia regional representative for the US health and human services department. Lal says it will bridge the translational research gap that exists between academic scientists and clinical programmes, to help take promising leads to the proof-ofconcept stage.

Despite being a nonprofit organization, the centre will be run as a business, and will be free beyond its $£ 90$-million seed funding to pursue partnerships with academics, companies, governments and philanthropic bod-

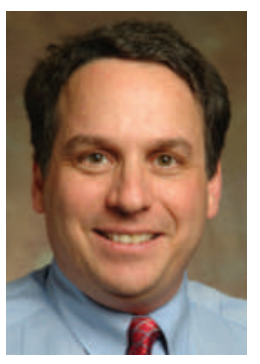
ies. The centre's portfolio will include high-risk research into diseases for which no vaccines are currently available, says Ted Bianco, director of technology transfer at the Wellcome Trust in London. It will also aim for more immediate pay-offs, such as improving existing vaccines that are too expensive or poorly adapted for distribution in hot, resource-poor countries, where maintaining a chain of refrigeration is complicated.

"The centre will bring the scientific and technical skills of an extremely advanced vaccine

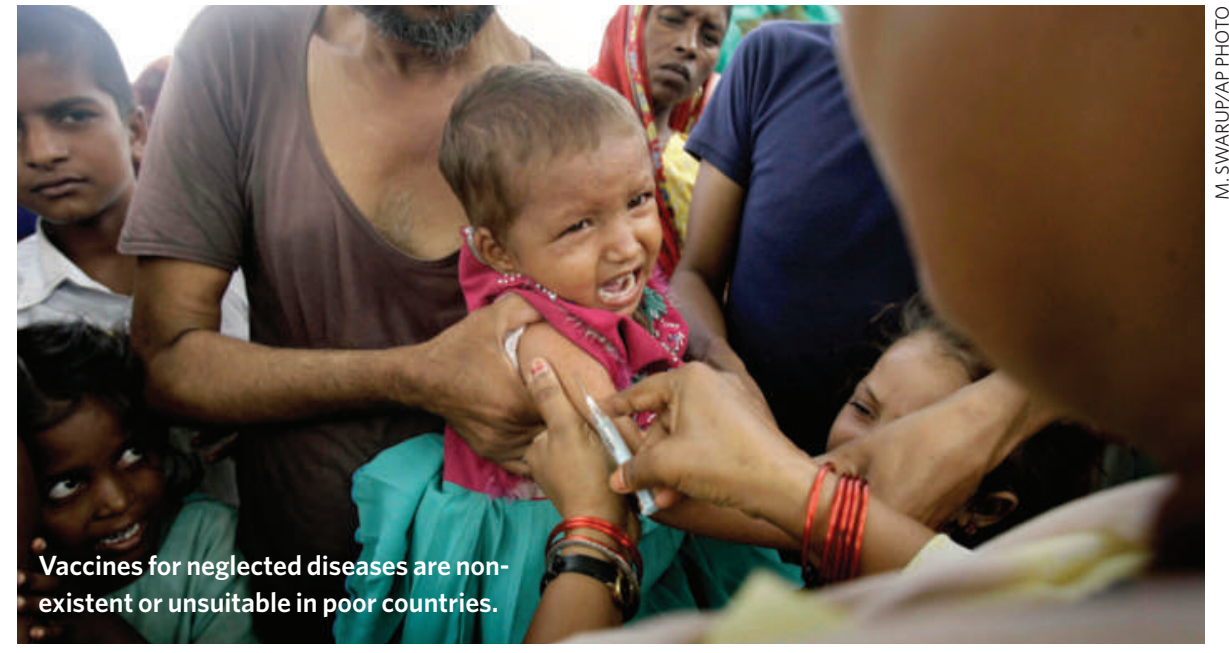

company like Merck to bear," says Marie-Paule Kieny, vaccine-research director at the World Health Organization (WHO) in Geneva, Switzerland, adding that the direct involvement of the Wellcome Trust confers considerable credibility on the venture's goals.

Prospects for vaccines in low-income countries have recently improved. Public-private partnerships have been set up to develop vaccines against the big killers, such as HIV/AIDS and malaria, and the drug firm Novartis last year opened an in-house, non-profit research institute in northern Italy to develop vaccines for diarrhoeal diseases (see Nature 451, 1037; 2008). The Geneva"We really want to based global health lower a lot of the partnership the GAVI barriers that exist Alliance, created in 2000, has also greatly for developing increased and accelerpromising ated the introduction products." and distribution of large - Mark Feinberg But the crucial missing component has been bringing academic development together with industrial expertise, says Bianco. "Merck are terrific partners to have," he says. "When making vaccines, know-how is hugely significant, and vaccines are a struggle to get into developing countries without it." As well as funding the centre, Merck will offer access to its own researchers, its technologies such as adjuvants and its expertise in clinical trials, says Mark Feinberg, the company's vice-president of medical affairs and policy.

The joint venture has yet to decide which diseases it will tackle, but will base the decisions on criteria such as scientific and technical feasibility, affordability and whether vaccine formulations will meet the field and other needs of the large procurement agencies such as the WHO, the United Nations Children's Fund (UNICEF) and the GAVI Alliance. One candidate being explored for vaccine suitability is the Group A Streptococcus bacterium, which causes some 400,000 deaths annually in poor countries but has attracted little research funding.

To start whittling down the list of potential candidates, Wellcome and Merck organized a meeting of scientists and other stakeholders in January this year at a research centre in Kilifi, Kenya, part of the Kenya Medical Research Institute (KEMRI). The two partners have also created an advisory group of external scientists chaired by David Heymann, a former assistant director-general of the WHO and now chairman of the UK Health Protection Agency.

The Indian centre will also collaborate with local pharmaceutical companies that can cheaply produce any vaccines it develops. That's novel, says Kieny, and may well pave the way for Western vaccine makers to allow generic versions of vaccines, such as those against human papillomavirus or pneumonia, which are available in rich countries but too expensive for poorer ones.

"Affordability will be key in the technical and other choices all along the product design and development path," says Feinberg. "We really want to lower a lot of the barriers that exist for developing promising products."

Declan Butler 